\title{
Structural, Surface Morphology and Optical Properties of ZnS Films by Chemical Bath Deposition at Various Zn/S Molar Ratios
}

\author{
Fei-Peng Yu, ${ }^{1}$ Sin-Liang Ou, ${ }^{1}$ Pin-Chuan Yao, ${ }^{2}$ Bing-Rui Wu, ${ }^{1}$ and Dong-Sing Wuu ${ }^{1,2}$ \\ ${ }^{1}$ Department of Materials Science and Engineering, National Chung Hsing University, 250 Kuo Kuang Road, \\ Taichung 40227, Taiwan \\ ${ }^{2}$ Department of Materials Science and Engineering, Da-Yeh University, Changhua 51591, Taiwan
}

Correspondence should be addressed to Dong-Sing Wuu; dsw@dragon.nchu.edu.tw

Received 13 December 2013; Revised 8 March 2014; Accepted 10 March 2014; Published 31 March 2014

Academic Editor: Sheng-Po Chang

Copyright (C) 2014 Fei-Peng Yu et al. This is an open access article distributed under the Creative Commons Attribution License, which permits unrestricted use, distribution, and reproduction in any medium, provided the original work is properly cited.

In this study, $\mathrm{ZnS}$ thin films were prepared on glass substrates by chemical bath deposition at various $\mathrm{Zn} / \mathrm{S}$ molar ratios from $1 / 50$ to $1 / 150$. The effects of $\mathrm{Zn} / \mathrm{S}$ molar ratio in precursor on the characteristics of $\mathrm{ZnS}$ films were demonstrated by $\mathrm{X}$-ray diffraction, scanning electron microscopy, optical transmittance, $\mathrm{X}$-ray photoelectron spectroscopy, and Fourier transform infrared spectrometry. It was found that more voids were formed in the $\mathrm{ZnS}$ film prepared using the precursor with $\mathrm{Zn} / \mathrm{S}$ molar ratio of $1 / 50$, and the other ZnS films showed the denser structure as the molar ratio was decreased from 1/75 to 1/150. From the analyses of chemical bonding states, the $\mathrm{ZnS}$ phase was indeed formed in these films. Moreover, the $\mathrm{ZnO}$ and $\mathrm{Zn}(\mathrm{OH})_{2}$ also appeared due to the water absorption on film surface during deposition. This would be helpful to the junction in cell device. With changing the $\mathrm{Zn} / \mathrm{S}$ molar ratio from $1 / 75$ to $1 / 150$, the $\mathrm{ZnS}$ films demonstrate high transmittance of $75-88 \%$ in the visible region, indicating the films are potentially useful in photovoltaic applications.

\section{Introduction}

Zinc sulfide (ZnS) is a II-VI compound semiconductor with a wide direct band gap $\left(E_{g}=3.6 \sim 3.8 \mathrm{eV}\right)$. Moreover, $\mathrm{ZnS}$ has the high refractive index $(2.35$ at $632 \mathrm{~nm})$ and high dielectric constant (9 at $1 \mathrm{MHz}$ ) [1]. As a result, it can be widely applied in the optoelectronic applications consisting of light emitting diodes with short wavelength, electroluminescent devices, and solar cells. For the photovoltaic applications, $\mathrm{ZnS}$ thin film is also transparent in all wavelengths of solar spectrum and has high absorption for the wavelength below $520 \mathrm{~nm}$ as compared to CdS. Many techniques including sputtering [2], molecular beam epitaxy [3], pulsed laser deposition [4], chemical vapor deposition [5], successive ionic layer adsorption and reaction [6], spray pyrolysis [7], and chemical bath deposition (CBD) $[1,8]$ have been proposed to fabricate the $\mathrm{ZnS}$ thin films. Among these methods, $\mathrm{CBD}$ is most attractive because it can be employed as the large-area growth without vapor deposition related to physical techniques and free of some inherent problems associated with high temperature fabrication [9].

For the ZnS growth by CBD process, a soluble salt of $\mathrm{Zn}$ ion and nonmetallic $\mathrm{S}$ source compound dissolved in an aqueous solution is required, reacting by the following equation: $\mathrm{Zn}^{2+}+\mathrm{S}^{2-} \rightarrow \mathrm{ZnS}, K_{\mathrm{sp}}=10^{-24.7}[10]$. Owing to the low solubility product of $\mathrm{Zn}^{2+}$ and $\mathrm{S}^{2-}$, $\mathrm{ZnS}$ precipitation will take place rapidly at very low concentration (homogeneous process), which results in the loose structure and poor transmittance in the thin film. However, the $\mathrm{ZnS}$ thin film with good uniformity and high transmittance can be achieved using the complex agents, such as trisodium citrate, ethylenediamine, and nitrilotriacetate (heterogeneous process). With the assistance of complex agents, the metal ions and negative ions were released slowly and then reacted to form the compound. The process is used to avoid the fast precipitation of the compound in the solution [11]. Moreover, 
the use of hydrazine hydrate as second ligand in the process can also enhance the homogeneity and adhesion of the film and increase the growth rate [9].

Up to now, the CBD-ZnS films are always formed by using $\mathrm{Zn}$-contained and S-contained solutions, which have the similar molar concentration to each other. For example, as the concentration of $\mathrm{Zn}$-contained solution was fixed, the same or 2-10 times concentration of S-contained solution was used in the CBD process. However, there are very few researches on the CBD-ZnS films by these two solutions with large difference in concentration.

In this study, the CBD technique was performed to prepare the $\mathrm{ZnS}$ films. By modifying the $\mathrm{Zn} / \mathrm{S}$ molar ratio from $1 / 50$ to $1 / 150$, the $S$-contained solutions with much higher concentrations than that of $\mathrm{Zn}$-contained solution were employed to form the $\mathrm{ZnS}$ films. This could be expected that more nucleation sites will appear during the $\mathrm{CBD}$ process for the formation of $\mathrm{ZnS}$ clusters. As a result, the quality of ZnS film will be better and the growth rate can be increased. The morphology, chemical bonding states, and structural and optical properties of these $\mathrm{ZnS}$ films have been investigated in detail.

\section{Experimental Procedure}

In our work, $\mathrm{ZnS}$ thin films were prepared on the glass and Si substrates by CBD method. The substrates were cleaned ultrasonically by detergent solution, acetone, and deionized water, respectively, to ensure the complete cleanness. For the CBD process, the aqueous solutions of zinc sulfate $\left(\mathrm{ZnSO}_{4}\right)$ and thiourea $\left(\mathrm{SC}\left(\mathrm{NH}_{2}\right)_{2}\right)$ were used to grow the $\mathrm{ZnS}$ films. The concentration of $\mathrm{ZnSO}_{4}$ solution was fixed at $1.4 \times$ $10^{-3} \mathrm{M}$, and the concentration of $\mathrm{SC}\left(\mathrm{NH}_{2}\right)_{2}$ solution was increased from 0.07 to $0.21 \mathrm{M}$, leading to the precursors with various $\mathrm{Zn} / \mathrm{S}$ molar ratios from $1 / 50$ to $1 / 150$ in the mixed solution. The $\mathrm{ZnS}$ films prepared using the precursors with various $\mathrm{Zn} / \mathrm{S}$ molar ratios of $1 / 50,1 / 75,1 / 100,1 / 125$, and $1 / 150$ are denoted as samples $\mathrm{A}, \mathrm{B}, \mathrm{C}, \mathrm{D}$, and $\mathrm{E}$, corresponding to the used $\mathrm{SC}\left(\mathrm{NH}_{2}\right)_{2}$ concentrations of $0.07,0.105,0.14,0.175$, and $0.21 \mathrm{M}$, respectively. Firstly, the $100 \mathrm{~mL}$ of $1.4 \times 10^{-3} \mathrm{M} \mathrm{ZnSO}_{4}$ and $26 \mathrm{~mL}$ of $28 \%-30 \% \mathrm{NH}_{4} \mathrm{OH}$ were mixed in a glass beaker by stirring for $10 \mathrm{~min}$ to form a stable complex with zinc ions. Next, the $\mathrm{SC}\left(\mathrm{NH}_{2}\right)_{2}$ with desired concentration was added to a $6 \mathrm{~mL} 98+\%$ hydrazine hydrate in another beaker by stirring for $10 \mathrm{~min}$. Then, these two solutions were poured into a glass tank and placed on a hotplate stirrer. For the films growth, the substrates were vertically immersed in the solution, and the reaction temperature was maintained at $85^{\circ} \mathrm{C}$. The substrates were taken out after 2 hours and followed by cleaning them with deionized water.

The crystal structures of $\mathrm{ZnS}$ films were examined by X-ray diffraction (XRD, PANalytical, X'Pert Pro MRD) and transmission electron microscopy (TEM, JEOL JEM-2100F). The $\mathrm{Cu} \mathrm{K}_{\alpha}$ line $(\lambda=1.541874 \AA)$ was applied for the source and $\mathrm{Ge}(220)$ was employed as the monochromator for XRD. The films morphology was investigated by a scanning electron microscopy (SEM, JEOL JSM-6700F). The transmittance spectra of the films were determined by the UV-Vis

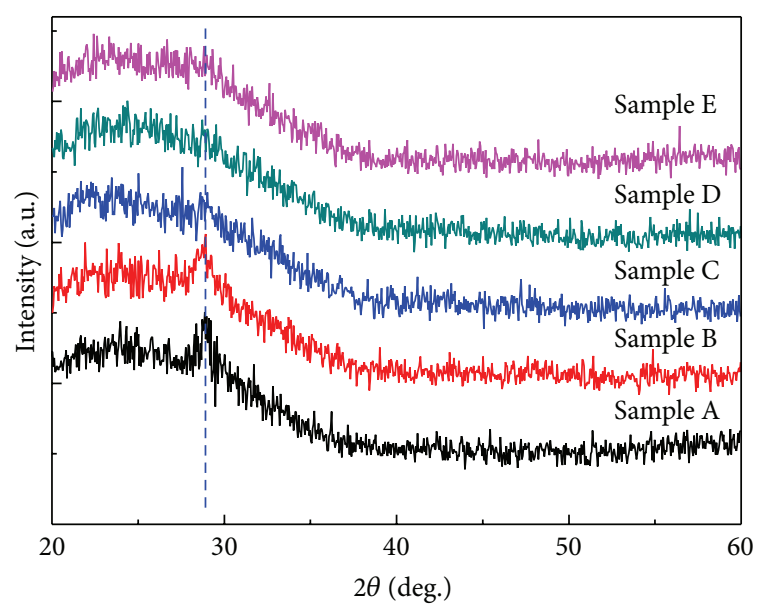

FIgURE 1: XRD patterns of samples A-E on glass substrates.

spectroscopy (UV-3101PC, Shimadzu). X-ray photoelectron spectroscopy (XPS, ULVAC-PHIPHI 5000) was used to analyze the film composition. Moreover, the existences of oxygen and carbon formed in the CBD process were also detected by XPS. The $\mathrm{Al} \mathrm{K}_{\alpha}(1486.7 \mathrm{eV})$ radiation was applied for the excitation source. The chemical bonding states of $\mathrm{ZnS}$ films were characterized by Fourier transform infrared spectrometry (FTIR, DA8.3, Bomem Inc.) using grazing incident angle reflectance method.

\section{Results and Discussion}

Generally, the crystal structures of ZnS exist in two forms, that is, the cubic (zincblende) and hexagonal (wurtzite) phases. The cubic $\mathrm{ZnS}$ is stable at room temperature, while the hexagonal $\mathrm{ZnS}$ is formed as the temperature is above $1020^{\circ} \mathrm{C}$ [12]. Figure 1 shows the results of XRD $\theta-2 \theta$ scan for samples A-E with increasing $2 \theta$ from $20^{\circ}$ to $60^{\circ}$. As the $\mathrm{ZnS}$ films deposited using the precursors with $\mathrm{Zn} / \mathrm{S}$ molar ratio of 1/100-1/150 (samples C, D and E), no obvious diffraction peak can be found except for a broad hump appeared in the $2 \theta$ range of $20-35^{\circ}$, indicating the amorphous phase was formed in these films. For the CBD process at $\mathrm{Zn} / \mathrm{S}$ molar ratio of $1 / 50-1 / 75$, only one diffraction peak around $2 \theta=28.5^{\circ}$ with low intensity appeared in these two spectra, which can be related to the cubic $\mathrm{ZnS}$ with (111) plane. Some reports have been proposed to demonstrate the $\mathrm{ZnS}$ grown by $\mathrm{CBD}$ method using $\mathrm{ZnSO}_{4}$ or $\mathrm{ZnCl}_{2}$ as precursors possessed the cubic structure $[13,14]$. As a result, the peak appeared in our result ought to belong to the cubic structure because of the low temperature process and the $\mathrm{ZnSO}_{4}$ precursor used in the chemical reaction. As well known, the film thickness is an important factor for the determination of crystalline structure in the film. According to our SEM results (as shown in below), the samples A and B both possessed a very thin thickness less than $70 \mathrm{~nm}$. As a result, there is no diffraction peak indexed to cubic or hexagonal $\mathrm{ZnS}$ phase in these two films except for the (111) plane. Although the hexagonal $\mathrm{ZnS}$ could present the better optical and electrical properties 


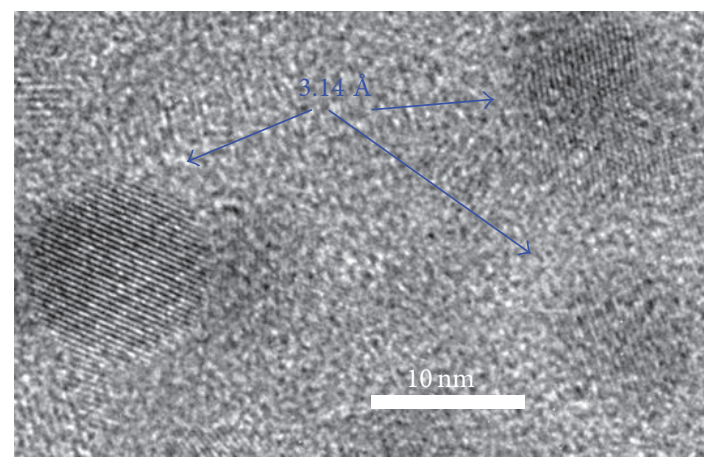

(a)

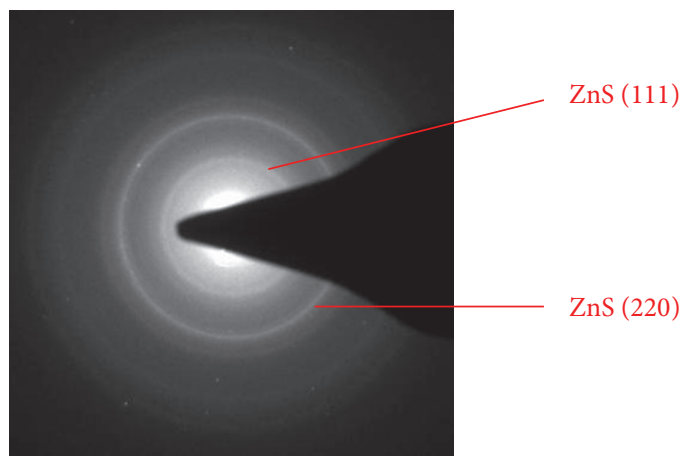

(b)

FIGURE 2: (a) High-resolution TEM bright field photograph and (b) electron diffraction pattern of sample B.

than those of cubic $\mathrm{ZnS}$, the hexagonal $\mathrm{ZnS}$ is relatively difficult to prepare. According to Gilbert et al. research [12], the high temperature (above $1020^{\circ} \mathrm{C}$ ) process was performed to fabricate the hexagonal $\mathrm{ZnS}$ bulk material. In fact, the CBD-ZnS films were usually prepared at low temperature (from room temperature to $90^{\circ} \mathrm{C}$ ). It indicates that the high temperature process is unsuitable for the preparation of $\mathrm{ZnS}$ film by using CBD method. Additionally, the hexagonal phase may be formed by performing the postannealing process to $\mathrm{ZnS}$ sample at high temperature. Nevertheless, based on previous research [15], the annealing process would induce the significant reduction in the optical transmittance of CBD-ZnS film, lowering the feasibility for the photovoltaic applications. On the other hand, although no characteristic peaks induced by the $\mathrm{Zn}(\mathrm{OH})_{2}$ or $\mathrm{ZnO}$ phase were detected in our result, these compounds were formed in the films by analyzing the bonding states in XPS measurements, as exhibited in the following discussion.

Figure 2(a) displays the high-resolution TEM image of sample B to check the formation of crystalline structure in $\mathrm{ZnS}$ films. It can be seen that there were some grains with uniform spherical shape in the image (marked by the blue arrows), and the size was measured to be about $8-10 \mathrm{~nm}$. This indicates the nanocrystalline structure was indeed existed in the film. In addition, the presence of nanocrystal grains without aggregation supported the XRD peak with low intensity presented in Figure 1. Moreover, we observed the $d$ spacing clearly appeared in the grains. From our calculation, these grains all have the similar $d$-spacing value about $3.14 \AA$, which can be indexed to the (111) plane of cubic ZnS. It is in good agreement with the XRD result. Except for the XRD and high-resolution TEM measurements, the electron diffraction pattern was also used to further analyze the phase of $\mathrm{ZnS}$ film (sample B). As shown in Figure 2(b), it indicates that the $\mathrm{ZnS}$ film possesses polycrystalline nature with the cubic phase, and the diffraction pattern rings are identified to $\mathrm{ZnS}$ (111) and $\mathrm{ZnS}(220)$.

Figures 3(a)-3(e) show the plain-view SEM images of ZnS films with various reaction conditions (samples AE). It was found that there were many voids in sample A, and the voids were reduced with increasing the $\mathrm{SC}\left(\mathrm{NH}_{2}\right)_{2}$ concentration, indicating that a denser structure on surface appeared in the $\mathrm{ZnS}$ films prepared using the precursors with
$\mathrm{Zn} / \mathrm{S}$ molar ratio of $1 / 75-1 / 150$. These surface states strongly influence the optical properties of ZnS film consisting of transmittance, absorbance, and reflection. Moreover, it is worth mentioning that the discontinuous film was emerged in sample A, revealing the aggregation of grains did not form the film in such reaction condition. This could lead to a leakage current as the $\mathrm{ZnS}$ film is used as the buffer layer for cell device. Except for sample A, the coalescence of grains was improved in the other samples (B-E), and the good adhesion of these films to the glass substrates was also observed. Crosssectional SEM images indicate that the thicknesses of sample $\mathrm{A}, \mathrm{B}, \mathrm{C}, \mathrm{D}$, and $\mathrm{E}$ are measured to be $92,63,60,61$, and $59 \mathrm{~nm}$, respectively, as shown in Figures 3(f) $-3(\mathrm{j})$. Obviously, at $\mathrm{Zn} / \mathrm{S}$ molar ratio of $1 / 50$ in the $\mathrm{CBD}$ process, the $\mathrm{ZnS}$ film has higher growth rate than the others. Besides, at $\mathrm{Zn} / \mathrm{S}$ molar ratio of $1 / 75-1 / 150$, the $\mathrm{ZnS}$ films have the similar growth rate to each other. This is because the $\mathrm{ZnS}$ films with $\mathrm{Zn} / \mathrm{S}$ molar ratio of $1 / 75 \sim 1 / 150$ all possess the dense structure (observed by SEM). The adhesion of CBD-ZnS film to the substrate is also an important factor for the photovoltaic applications. Based on our results, the adhesion of CBD-ZnS film to the substrate became worse as the $\mathrm{Zn} / \mathrm{S}$ molar ratio was decreased. Actually, in this study, the adhesions of these $\mathrm{ZnS}$ films are good enough to use in the photovoltaic applications, even for the ZnS film with a lower Zn/S molar ratio of 1/150. However, further decreasing the $\mathrm{Zn} / \mathrm{S}$ molar ratio to $1 / 200$ and $1 / 300$, these two $\mathrm{ZnS}$ films possessed very poor adhesion, which were unsuitable for the fabrication of optoelectronic devices. Besides, as the $\mathrm{Zn} / \mathrm{S}$ molar ratio was reduced to $1 / 200$ and $1 / 300$, it would result in a lot of $\mathrm{Zn}(\mathrm{OH})_{2}$ formation in the $\mathrm{ZnS}$ sample. The excessive $\mathrm{Zn}(\mathrm{OH})_{2}$ formation can decrease the optical transmittance of $\mathrm{ZnS}$ film, causing the degradation in the device performance.

Figure 4(a) shows the transmittance spectra of samples A-E recorded in a wavelength range of $200-1000 \mathrm{~nm}$. We can observe that the sample $\mathrm{A}$ has a lower transmittance than that of samples B-E in the spectral range of $350-1000 \mathrm{~nm}$. For the $\mathrm{ZnS}$ films deposited using the precursors with $\mathrm{Zn} / \mathrm{S}$ molar ratio of $1 / 75-1 / 150$ (samples B-E), it can be found that the transmittance is higher than $75 \%$ when the wavelength is larger than $360 \mathrm{~nm}$ and reaches at a maximum value about $88 \%$. According to the results of film adhesion and optical transmittance, it indicates that the $\mathrm{ZnS}$ film with $\mathrm{Zn} / \mathrm{S}$ molar 


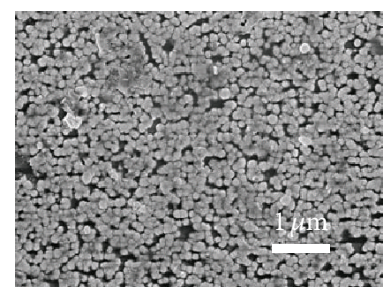

(a)

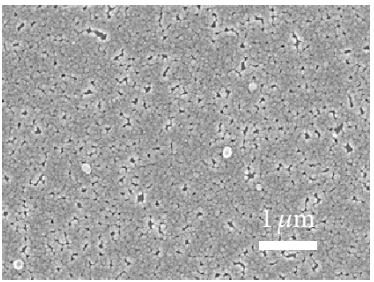

(b)

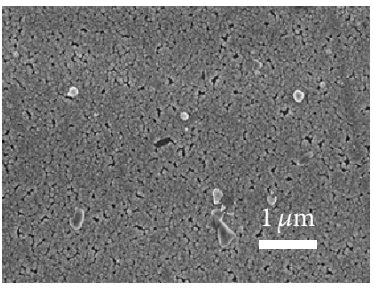

(c)

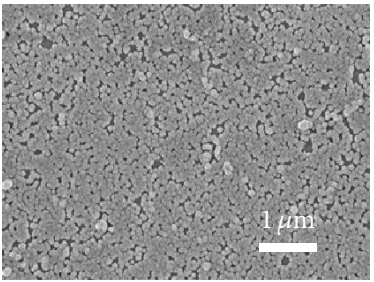

(d)

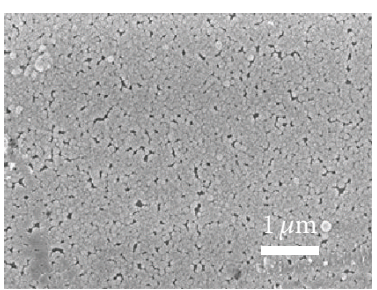

(e)

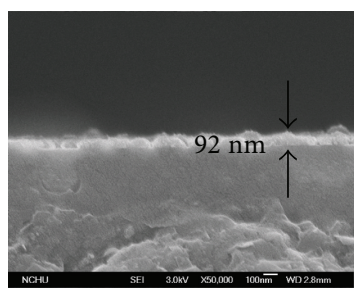

(f)

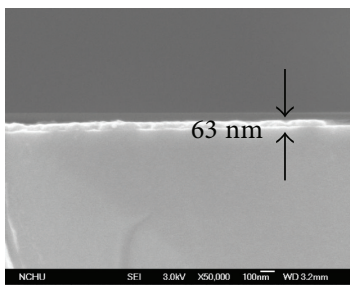

(g)

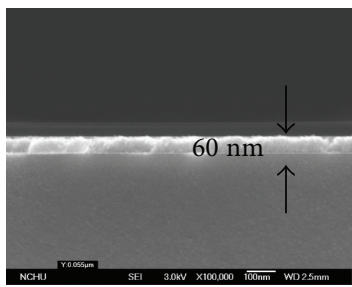

(h)

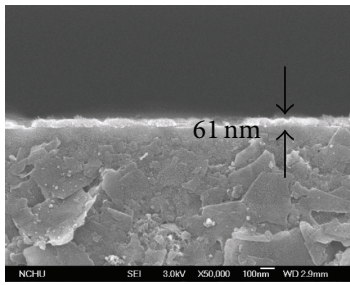

(i)

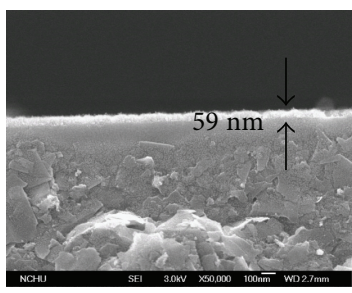

(j)

Figure 3: ((a)-(e)) Plane-view SEM images and ((f)-(j)) cross-sectional SEM images of samples A-E.

ratio of $1 / 75$ is most suitable for use in the buffer layer of solar energy device. On the other hand, all $\mathrm{ZnS}$ films exhibit the clear absorption edges near 310-320 nm. From the Beer-Lambert law [16], the absorption coefficient $(\alpha)$ can be obtained by the following equation:

$$
\alpha=\frac{1}{t} \ln \left(\frac{1}{T}\right),
$$

where $t$ is the film thickness and $T$ the optical transmittance. Because $\mathrm{ZnS}$ belongs to the direct band gap semiconductor, the relationship between $\alpha$ and incident photon energy $(h v)$ is represented as [17]

$$
\alpha h v=A\left(h v-E_{g}\right)^{1 / 2},
$$

where $A$ is the constant and $E_{g}$ the band gap of semiconductor. In the curve of $\alpha^{2}$ versus $h v$, the band gap is determined by extrapolating the linear region near the onset, as shown in Figure 4(b). The band gaps of these samples are about 3.85$3.86 \mathrm{eV}$, which agree well with that of $\mathrm{ZnS}$ single crystal.

During the growth process of CBD-ZnS, not only the $\mathrm{Zn}$ and $\mathrm{S}$ were found in the film, but also the elements of 


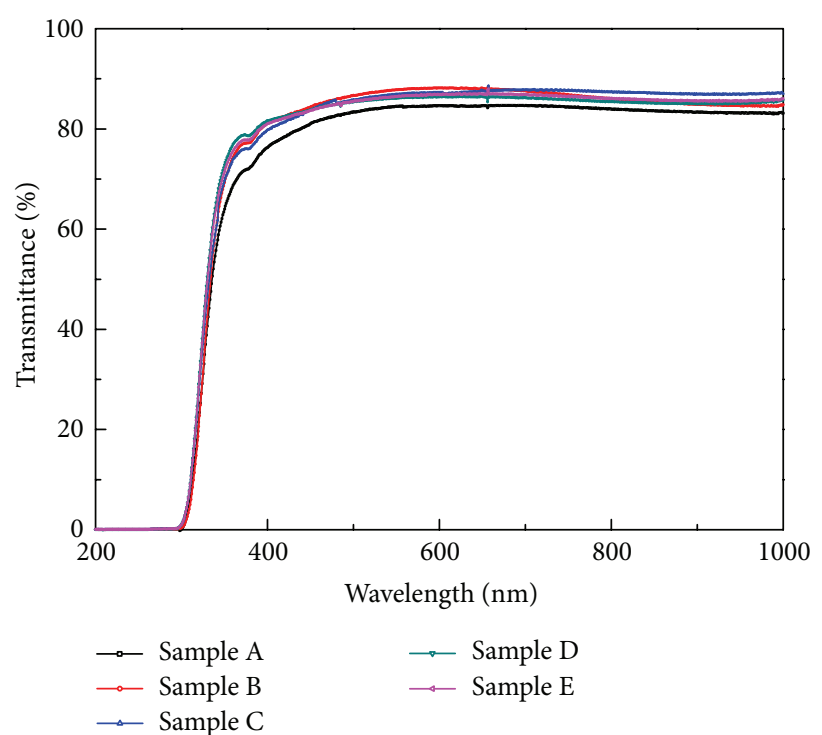

(a)

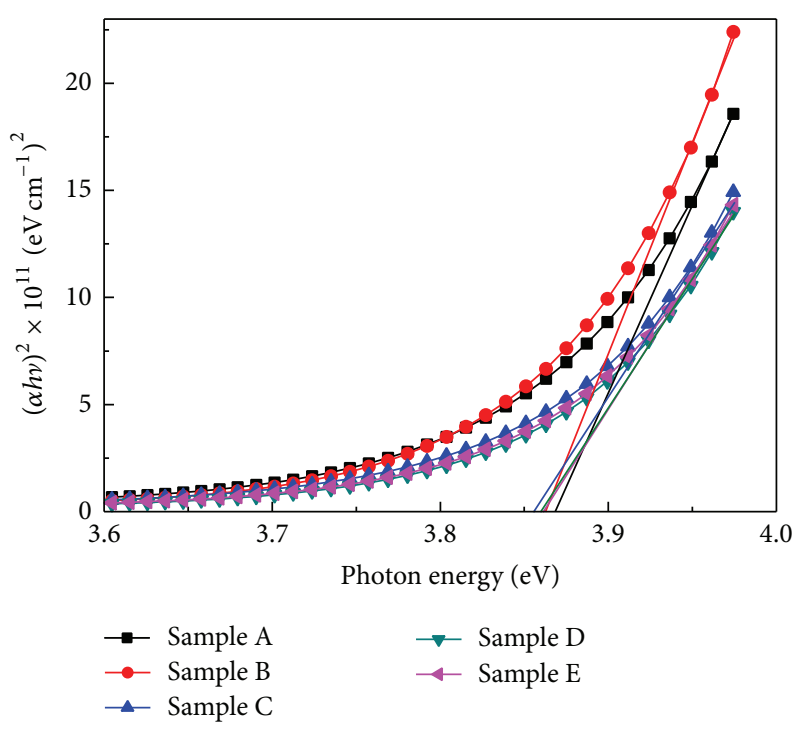

(b)

Figure 4: (a) Transmittance spectra with the measured wavelength ranging from 200 to $1000 \mathrm{~nm}$ and (b) the plots of ( $\alpha h v)^{2}$ versus photon energy for samples A-E.

$\mathrm{O}$ and $\mathrm{C}$ appeared. Actually, there were probably a lot of oxygen existed in the $\mathrm{ZnS}$ layer via the formations of $\mathrm{ZnO}$ and $\mathrm{Zn}(\mathrm{OH})_{2}$ by the following chemical reactions:

$$
\begin{gathered}
\mathrm{Zn}^{2+}+2 \mathrm{OH}^{-} \Longleftrightarrow \mathrm{Zn}(\mathrm{OH})_{2} \\
\mathrm{Zn}(\mathrm{OH})_{2} \Longleftrightarrow \mathrm{ZnO}+\mathrm{H}_{2} \mathrm{O}
\end{gathered}
$$

On the other hand, the carbon in $\mathrm{ZnS}$ films could be resulted from the initial precursor of thiourea. According to the past research [18], it demonstrated that some amount of $\mathrm{ZnO}$ and $\mathrm{Zn}(\mathrm{OH})_{2}$ in the $\mathrm{ZnS}$ buffer was required, which can provide a good junction to the cell and create an efficient device. As a result, the XPS measurements were performed to check the existence of $\mathrm{ZnO}$ or $\mathrm{Zn}(\mathrm{OH})_{2}$ in these $\mathrm{ZnS}$ films prepared using the precursors with various $\mathrm{Zn} / \mathrm{S}$ molar ratios. Figures 5(a)-5(e) display the XPS results of O1s spectra for the samples A-E. All XPS spectra of the $\mathrm{ZnS}$ films were fitted well with Gaussian functions. The fitting results revealed that the O1s peaks centered at 531.3-531.8 eV, which was deconvoluted into three Gaussian peaks centered at $530.3 \mathrm{eV}\left(\mathrm{Zn}(\mathrm{OH})_{2}\right)$, $531.4 \mathrm{eV}(\mathrm{ZnO})$, and $533.3 \mathrm{eV}$ (C-O bond), respectively. Based on the quantitative analyses, we found only very few $\mathrm{C}-\mathrm{O}$ bonds were formed in the $\mathrm{ZnS}$ films. It proved that the main formations of $\mathrm{ZnS}, \mathrm{Zn}(\mathrm{OH})_{2}$, and $\mathrm{ZnO}$ were included in these films, leading to the assistance for cell device performance. On the other hand, it can be observed that the peak positions of O1s were $531.8,531.5,531.4,531.3$, and $531.3 \mathrm{eV}$, respectively, as the $\mathrm{ZnS}$ films were prepared using the precursors with $\mathrm{Zn} / \mathrm{S}$ molar ratios of $1 / 50,1 / 75,1 / 100,1 / 125$, and $1 / 150$. It is well known that the peak position of O1s can be used to determine the amount of oxygen atoms in the film. From our results, a shift of O1s binding energy in the direction toward lower energy side was found with decreasing the $\mathrm{Zn} / \mathrm{S}$ molar ratio in the precursor, which indicated that the number of oxygen atom in the ZnS film was decreased. Obviously, the lower the $\mathrm{Zn} / \mathrm{S}$ molar ratio in precursor, the more the $\mathrm{ZnS}$ nucleation could be. This will induce the less $\mathrm{Zn}$ atoms provided for oxygen atoms to form the $\mathrm{ZnO}$ compound, resulting in the reduction of oxygen content in the $\mathrm{ZnS}$ film.

To investigate the chemical bonding states of these films, the FTIR analyses in a transmittance mode were applied for ZnS films grown on the Si substrates with high resistance. Figure 6 shows the FTIR spectra measured for samples AE. The absorption band located at $615 \mathrm{~cm}^{-1}$ can be attributed to the formation of $\mathrm{ZnS}$ phase [19]. Due to the choice of Si substrate, it caused the weak peak at $799.5 \mathrm{~cm}^{-1}$ related to the $\mathrm{Si}-\mathrm{O}$ bond. The absorption band appeared at $1086 \mathrm{~cm}^{-1}$ was resulted from the $\mathrm{Zn}-\mathrm{OH}$ vibrations. The band at $1600 \mathrm{~cm}^{-1}$ and broad peak in the region of $3000-3600 \mathrm{~cm}^{-1}$ were induced by the stretching and bending vibrations of hydroxyl groups, respectively, indicating that the $\mathrm{ZnS}$ could absorb the water on the film surface during the CBD process [20]. Moreover, the band at $2926 \mathrm{~cm}^{-1}$ can be ascribed to the $\mathrm{C}-\mathrm{H}$ stretching vibrations [21]. Because the corresponded wavenumber of $\mathrm{Zn}-\mathrm{O}$ bond is outside the measured range, there is no $\mathrm{Zn}-\mathrm{O}$ peak formed in the FTIR spectra. Based on the FTIR results, it proves the $\mathrm{ZnS}$ phase is certainly formed in these films. Furthermore, the oxygen and carbon are also found in these films by FTIR measurement. This agrees with the result from XPS spectra, as displayed in Figure 5.

\section{Conclusion}

In summary, the technique of chemical bah deposition was performed to grow the $\mathrm{ZnS}$ thin films. As the concentration of $\mathrm{ZnSO}_{4}$ solution was fixed, the $\mathrm{Zn} / \mathrm{S}$ molar ratio of precursor was varied from $1 / 50$ to $1 / 150$ by changing the concentration 


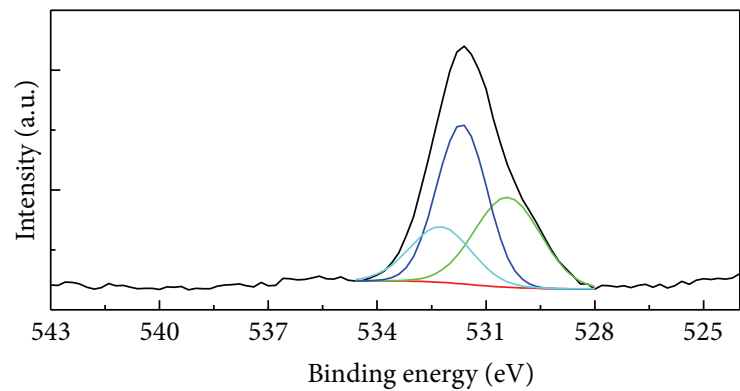

(a)

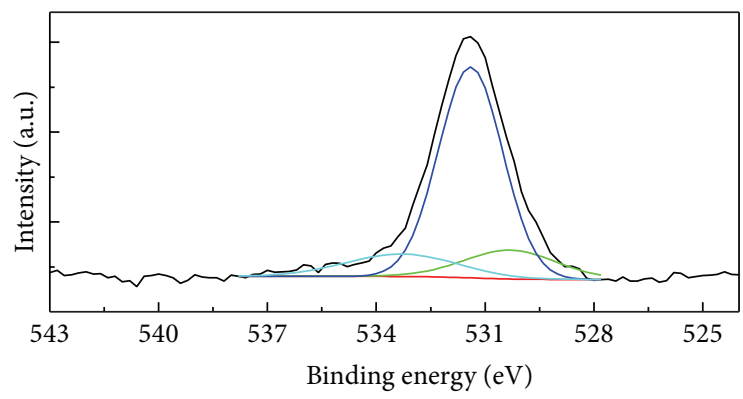

(c)

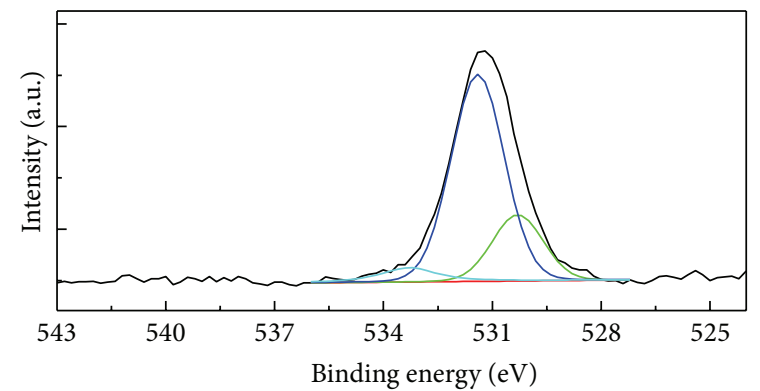

(b)

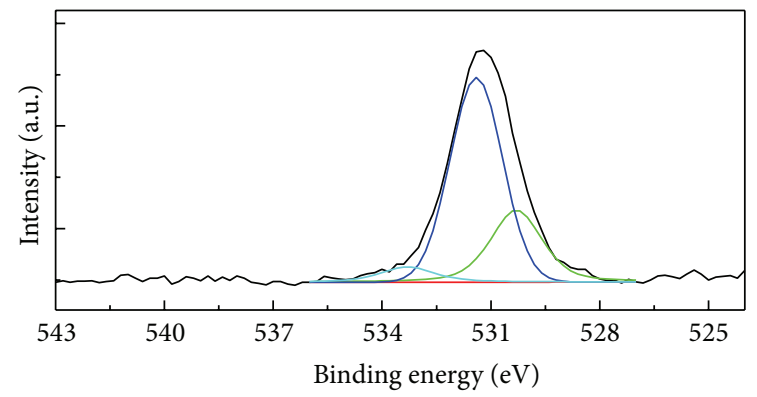

(d)

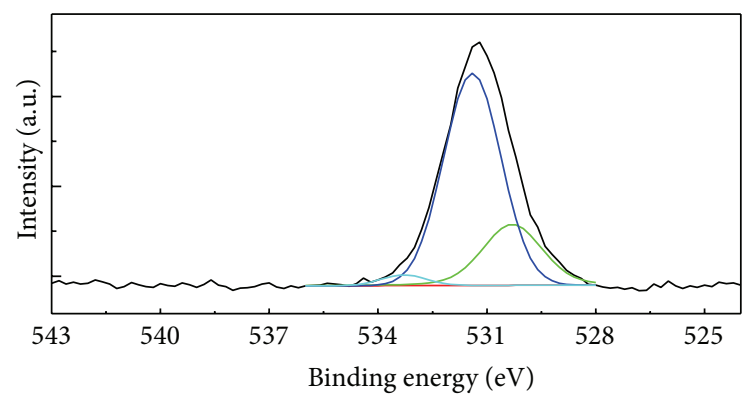

(e)

Figure 5: ((a)-(e)) XPS spectra of O1s core level for samples A-E.

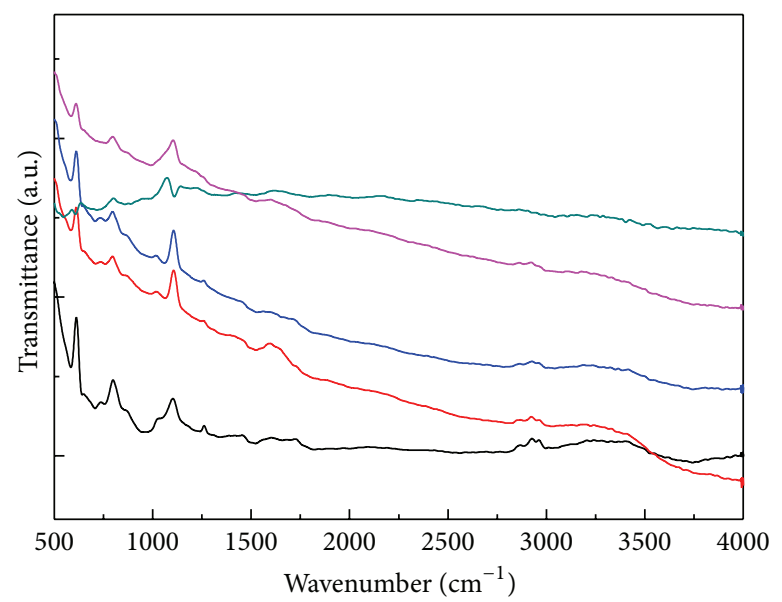

$\begin{array}{ll}\text { Sample A } & \text { Sample D } \\ \text { Sample B } & \text { Sample E } \\ \text { Sample C } & \end{array}$

FIGURE 6: FTIR spectra using a transmittance mode for samples A-E. 
of $\mathrm{SC}\left(\mathrm{NH}_{2}\right)_{2}$ solution. The $\mathrm{ZnS}, \mathrm{ZnO}$, and $\mathrm{Zn}(\mathrm{OH})_{2}$ were all found in these films. Because of the surface absorption of water in the films growth, it leaded to the formations of $\mathrm{ZnO}$ and $\mathrm{Zn}(\mathrm{OH})_{2}$. At the $\mathrm{Zn} / \mathrm{S}$ molar ratio of $1 / 75-1 / 150$, the $\mathrm{ZnS}$ films presented a high transmittance of $75-88 \%$ in the range of visible wavelength (360-1000 nm), and their optical band gaps were measured to be about $3.85-3.86 \mathrm{eV}$. Based on the results of film adhesion and optical transmittance, it reveals that the $\mathrm{ZnS}$ film with $\mathrm{Zn} / \mathrm{S}$ molar ratio of 1/75 is most suitable as the buffer layers in the photovoltaic device.

\section{Conflict of Interests}

The authors declare that there is no conflict of interests regarding the publication of this paper.

\section{Acknowledgment}

This research was supported by the National Science Council of Taiwan, Republic of China, under Contract no. NSC 992221-E-005-101-MY3.

\section{References}

[1] K. Ahn, J. H. Jeon, S. Y. Jeong et al., "Chemical bonding states and atomic distribution within $\mathrm{Zn}(\mathrm{S}, \mathrm{O})$ film prepared on CIGS/Mo/glass substrates by chemical bath deposition," Current Applied Physics, vol. 12, no. 6, pp. 1465-1469, 2012.

[2] D. H. Hwang, J. H. Ahn, K. N. Hui, K. S. Hui, and Y. G. Son, "Structural and optical properties of $\mathrm{ZnS}$ thin films deposited by RF magnetron sputtering," Nanoscale Research Letters, vol. 7, article 26, pp. 1-13, 2012.

[3] J. P. Bosco, S. B. Demers, G. M. Kimball, N. S. Lewis, and H. A. Atwater, "Band alignment of epitaxial $\mathrm{ZnS} / \mathrm{Zn} 3 \mathrm{P} 2$ heterojunctions," Journal of Applied Physics, vol. 112, no. 9, Article ID 093703, 2012.

[4] S. Yano, R. Schroeder, H. Sakai, and B. Ullrich, "High-electricfield photocurrent in thin-film ZnS formed by pulsed-laser deposition," Applied Physics Letters, vol. 82, no. 13, pp. 20262028, 2003.

[5] M. W. Huang, Y. W. Cheng, K. Y. Pan, C. C. Chang, F. S. Shieu, and H. C. Shih, "The preparation and cathodoluminescence of ZnS nanowires grown by chemical vapor deposition," Applied Surface Science, vol. 261, pp. 665-670, 2012.

[6] G. Xu, S. Ji, C. Miao, G. Liu, and C. Ye, "Effect of ZnS and CdS coating on the photovoltaic properties of CuInS2-sensitized photoelectrodes," Journal of Materials Chemistry, vol. 22, no. 11, pp. 4890-4896, 2012.

[7] K. Nagamani, N. Revathi, P. Prathap, Y. Lingappa, and K. T. R. Reddy, "Al-doped ZnS layers synthesized by solution growth method," Current Applied Physics, vol. 12, no. 2, pp. 380-384, 2012.

[8] G. L. Agawane, S. W. Shin, M. S. Kim et al., "Green route fast synthesis and characterization of chemical bath deposited nanocrystalline ZnS buffer layers," Current Applied Physics, vol. 13, no. 5, pp. 850-856, 2013.

[9] P. O'Brien and J. McAleese, "Developing an understanding of the processes controlling the chemical bath deposition of $\mathrm{ZnS}$ and CdS," Journal of Materials Chemistry, vol. 8, no. 11, pp. 23092314, 1998.
[10] F. A. Cotton and G. Wilkinson, Advanced Inorganic Chemistry, John Wiley \& Sons, New York, NY, USA, 4th edition, 1980.

[11] P. Roy, J. R. Ota, and S. K. Srivastava, "Crystalline ZnS thin films by chemical bath deposition method and its characterization," Thin Solid Films, vol. 515, no. 4, pp. 1912-1917, 2006.

[12] B. Gilbert, B. H. Frazer, H. Zhang et al., "X-ray absorption spectroscopy of the cubic and hexagonal polytypes of zinc sulfide," Physical Review B-Condensed Matter and Materials Physics, vol. 66, no. 24, Article ID 245205, 2002.

[13] A. Goudarzi, G. M. Aval, R. Sahraei, and H. Ahmadpoor, "Ammonia-free chemical bath deposition of nanocrystalline ZnS thin film buffer layer for solar cells," Thin Solid Films, vol. 516, no. 15, pp. 4953-4957, 2008.

[14] J. Cheng, D. F. Fan, H. Wang, B. W. Liu, Y. Zhang, and H. Yan, "Chemical bath deposition of crystalline ZnS thin films," Semiconductor Science and Technology, vol. 18, no. 7, pp. 676679, 2003.

[15] F. Göde, "Annealing temperature effect on the structural, optical and electrical properties of ZnS thin films," Physica B: Condensed Matter, vol. 406, no. 9, pp. 1653-1659, 2011.

[16] J. D. J. Ingle and S. R. Crouch, Spectrochemical Analysis, Prentice Hall, New Jersey, NJ, USA, 1988.

[17] A. Antony, K. V. Murali, R. Manoj, and M. K. Jayaraj, “The effect of the $\mathrm{pH}$ value on the growth and properties of chemical-bathdeposited ZnS thin films," Materials Chemistry and Physics, vol. 90, no. 1, pp. 106-110, 2005.

[18] R. N. Bhattacharya, M. A. Contreras, and G. Teeter, "18.5\% Copper indium gallium diselenide (CIGS) device using singlelayer, chemical-bath-deposited $\mathrm{ZnS}(\mathrm{O}, \mathrm{OH})$," Japanese Journal of Applied Physics: Letters B, vol. 43, no. 11, pp. L1475-L1476, 2004.

[19] H. Yang, J. Zhao, L. Song et al., "Photoluminescent properties of ZnS:Mn nanocrystals prepared in inhomogeneous system," Materials Letters, vol. 57, no. 15, pp. 2287-2291, 2003.

[20] B. Mokili, Y. Charreire, R. Cortes, and D. Lincot, "Extended Xray absorption fine structure studies of zinc hydroxo-sulphide thin films chemically deposited from aqueous solution," Thin Solid Films, vol. 288, no. 1-2, pp. 21-28, 1996.

[21] M. L. Larsson, A. Holmgren, and W. Forsling, "Xanthate adsorbed on ZnS studied by polarized FTIR-ATR spectroscopy," Langmuir, vol. 16, no. 21, pp. 8129-8133, 2000. 

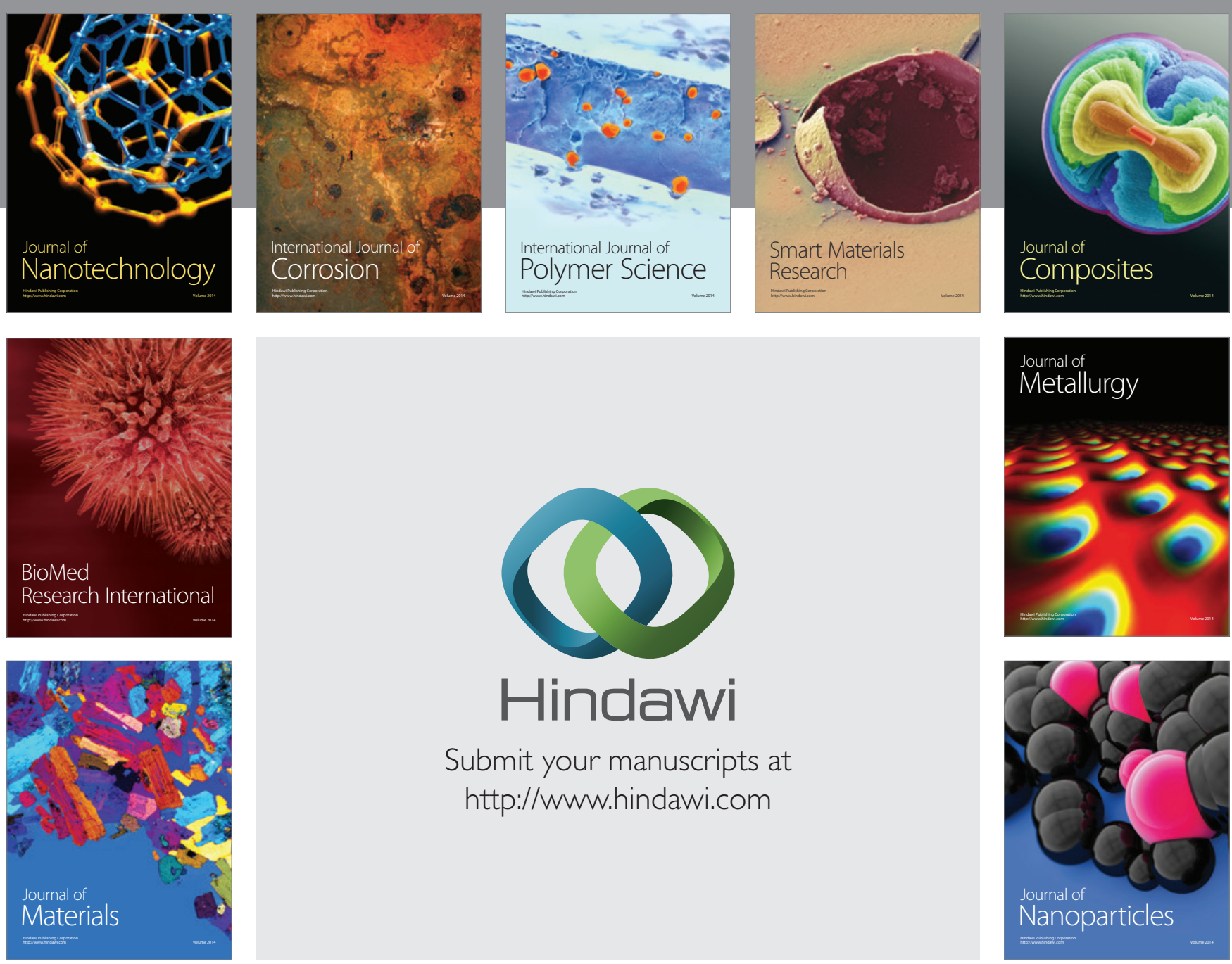

Submit your manuscripts at http://www.hindawi.com
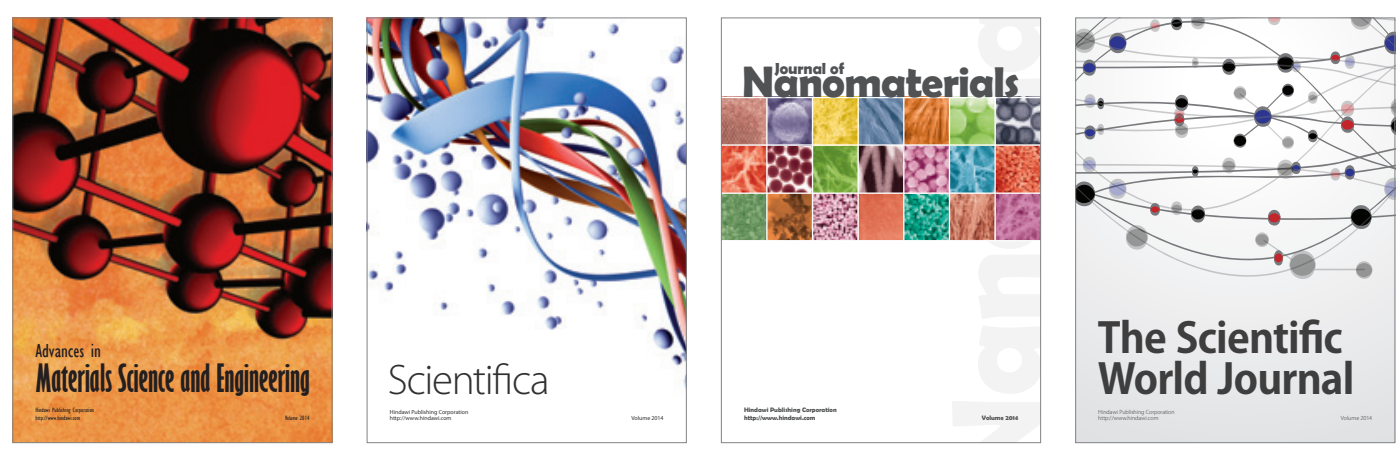

\section{The Scientific World Journal}
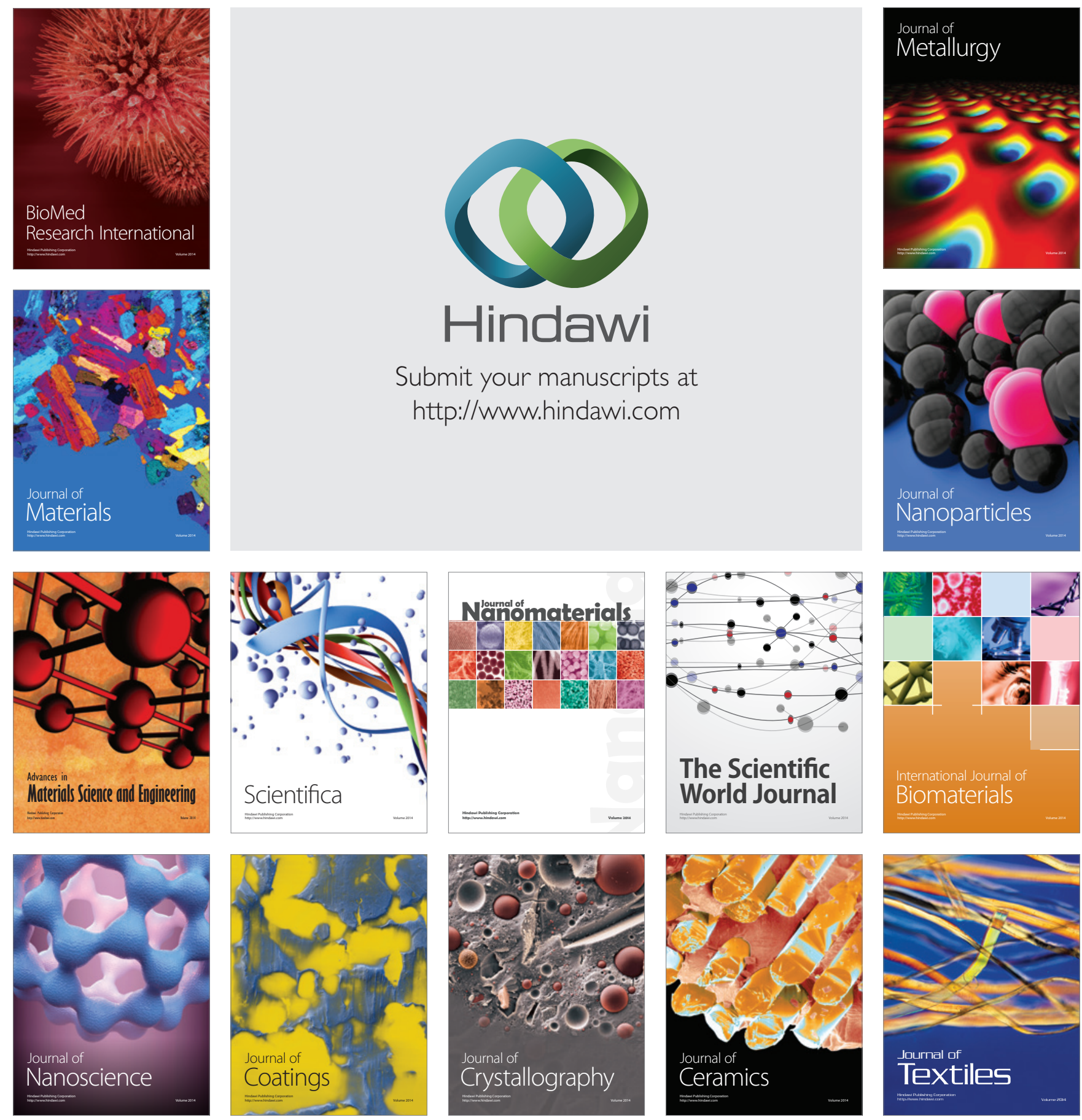